\title{
Textures that we like to touch: An experimental study of aesthetic preferences for tactile stimuli
}

\author{
Roberta Etzi ${ }^{\mathrm{a}, \mathrm{b}, *}$, Charles Spence ${ }^{\mathrm{b}}$, Alberto Gallace ${ }^{\mathrm{a}}$ \\ a Department of Psychology, University of Milan-Bicocca, Italy \\ ${ }^{\mathrm{b}}$ Crossmodal Research Laboratory, Department of Experimental Psychology, Oxford University, Oxford, UK
}

Received 10 October 2013

Available online 3 October 2014

\section{Introduction}

Aesthetic judgments constitute an important part of our everyday lives. Each and every day, we use aesthetic terms in order to describe the stimuli in our surroundings and the concept of "beauty" is often adopted in order to justify many of our choices. Interestingly, this is not only true in the world of tangible objects, but also in the field of science (e.g., Crick, 1988; Gallace \& Spence, 2011a; Galzigna, 1993, for the use of the concept of beauty in the selection of scientific theories). Despite its profound importance for our survival and well-being, the sense of touch has been little investigated by scientists, at least when compared to research on the other senses, such as vision and audition (see Gallace \& Spence, 2011b, 2014, on this point). This is particularly true for the topic of aesthetics. This neglect might depend on the common attitude not to attri-bute the concept of "beauty" to the sense of touch (Coleman, 1965; Gallace \& Spence, 2011b, 2014). However, it could also be related to the lack of a proper lexicon with which to describe tactile sensations (e.g., Bhushan, Rao, \& Lohse, 1997; Guest et al., 2011; Ripin \& Lazarsfeld, 1937). Nevertheless, the dictionary definition of 'beauty' refers to all of the senses, ${ }^{1}$ and those who are visually-impaired are perfectly capable of expressing aesthetic judgments regarding what they feel by means of their sense of touch (e.g., Coleman, 1965), just as sighted individuals are.

Here, it should be noted that the study of tactile aesthetics is affected by some practical difficulties, especially when it comes to sourcing the appropriate stimuli to be used within an experimental setting. Previously, the majority of scientists

\footnotetext{
* Corresponding author. Address: Department of Psychology, University of Milan-Bicocca, P.zza dell'Ateneo Nuovo, 1, 20126 Milan, Italy. E-mail address: roberta.etzi@unimib.it (R. Etzi).

1 "Beauty" has been defined as the quality of being pleasing to the sense or to the mind (Oxford Advanced Learner's Dictionary, 2005, Oxford University Press).
} 
interested in the more discriminative aspects of tactile perception have often used 'sandpaper' of different grit values as the stimuli in their psychophysical experiments. This choice was primarily driven to the ease with which this material can be obtained, and the fact that it comes in many objective different and standardized versions, varying in terms of their grit value (Bergmann Tiest \& Kappers, 2006). By contrast, as far as the majority of textures that we interact with on a daily basis are concerned, it is very complex to analyze how their physical attributes vary (e.g., smoothness, softness) and consequently how they affect individuals' perceptual responses (e.g., see Spence \& Gallace, 2008).

Understanding tactile aesthetics likely requires an investigation of the pleasant aspects of touch, which have been shown to be mediated, among other factors, by the neural transmission of a group of thin and unmyelinated fibres known as Ctactile afferents (CTs; Löken, Wessberg, Morrison, McGlone, \& Olausson, 2009; McGlone, Vallbo, Olausson, Löken, \& Wessberg, 2007; McGlone \& Reilly, 2010; McGlone, Wessberg, \& Olausson, 2014). These fibers respond more vigorously to slow (1-10 cm/s; Löken et al., 2009; Vallbo, Olausson, \& Wessberg, 1999) and light stimulation (0.3-2.5 mN; Vallbo et al., 1999), and are present only in the hairy skin (Liu et al., 2007; Vallbo et al., 1999). A number of studies have demon-strated that the gentle and slow stimulation of the hairy skin is perceived as more pleasant than the stimulation of the gla-brous skin (Essick et al., 2010; Guest et al., 2011; Löken et al., 2009). It is also worth noting here that the stimulation of the glabrous skin can be perceived as pleasant too (Klöcker, Arnould, Penta, \& Thonnard, 2012; Klöcker, Wiertlewski, Théate, Hayward, \& Thonnard, 2013). In fact, $A \beta$ fibers (that are present in both the hairy and glabrous skin) also seem to play a key role in the transmission of the pleasant aspects of touch by conveying discriminative information (e.g., concerning the speed and force of stimulation; McGlone et al., 2007, 2014) to the brain.

Importantly, when the hairy skin of healthy participants is stimulated it is inevitable that the $C T$ and $A \beta$ fibers are activated concurrently. However, the stimulation of these two kinds of fibers elicits stronger activations in different brain areas. More specifically, the application of pleasant stimuli to the glabrous skin (e.g., palm) activates the somatosensory cortex, the mid/anterior insular cortices (McGlone et al., 2012) and the orbitofrontal cortex (OFC; Francis et al., 1999; Rolls et al., 2003), whereas pleasant stimuli delivered to the hairy skin give rise to a greater activation of the mid/anterior OFC (McGlone et al., 2012), the pregenual anterior cingulate cortex (pgACC; Lindgren et al., 2012), and of the posterior insular cortex (Björnsdotter, Löken, Olausson, Vallbo, \& Wessberg, 2009; McGlone et al., 2012; Morrison, Björnsdotter, \& Olausson, 2011; Olausson et al., 2002, 2008). Interestingly, the insular cortex seems to be involved in maintaining the homeostatic con-trol over the body (Craig, 2002, 2009; Paulus, 2007) and it has been suggested to be the target of CT projections (Björnsdotter, Morrison, \& Olausson, 2010; Björnsdotter et al., 2009; Morrison et al., 2011; Olausson et al., 2002, 2008; see also Andrew, 2010, for a neurophysiological study on the projections of CT afferents in animals). Furthermore, it is also worth mentioning that the cortical areas activated during the pleasant stimulation of the hairy skin are among the evolutionarily oldest in the mammalian brain. This observation might be taken to suggest the presence of a link between hedonic tactile sensations and the primitive nature of touch, and also that our hedonic response to tactile stimuli might be innately determined (Gallace \& Spence, 2011a; McGlone et al., 2012).

As far as the brain mechanisms of tactile hedonic judgments are concerned, there is evidence to suggest a dominance of the right hemisphere in the processing of the pleasantness of tactile stimuli (Francis et al., 1999). However, it is still unclear how exactly different neural fibres and brain areas contribute to our aesthetic tactile judgments. Similarly, it is not well known how hedonic judgements are modulated by the way in which tactile stimuli are delivered to the skin (i.e., either actively or passively). Research focused on the role of active and passive exploration in the case of pleasant touch has revealed that being touched by another individual (passive touch), is more pleasant and more intense than when the same stimulation is self-delivered to our own body (Guest et al., 2009, 2011). This effect might also be attributable to the different sensitivity of the skin during the execution of movements (Bays \& Wolpert, 2007). In fact, a large body of evidence has shown that self-generated movements (as when we are engaged in active exploration) result in an attenuation of tactile sensitivity, a phenomenon known as 'sensory suppression' (Bays, Flanagan, \& Wolpert, 2006; Bays \& Wolpert, 2007; Chapman, Bushnell, Miron, Duncan, \& Lund, 1987; Gallace, Zeeden, Röder, \& Spence, 2010). The relevance of sensory suppression can easily be appreciated by simply noticing how difficult it is to tickle oneself (Blakemore, Wolpert, \& Frith, 1998). Nevertheless, it has been shown that some forms of tactile sensory suppression are context-dependent and do not occur when the purpose of the movement is actually to gain information about a surface (Juravle, McGlone, \& Spence, 2013). Despite the fact that a large number of studies regarding the relationship between active and passive touch has been published to date, it is still somewhat unclear how exactly these two modes of exploration affect the perceived pleasantness and consequently an observer's aesthetic judgments of tactile stimuli that happen to be presented to the skin surface.

Here, we report on two experiments where aesthetic preferences for surface textures were investigated in neurologically healthy individuals. Specifically, our aim was to assess how aesthetic judgments vary as a function of the stimulation of different body sites, and of the type of exploration (i.e., active vs. passive). On the basis of the literature on the more social aspects of touch (see Gallace \& Spence, 2010, 2014; Hertenstein, Keltner, App, Bulleit, \& Jaskolka, 2006, for reviews) as well as a number of previous studies where pleasant tactile stimuli were presented (Guest et al., 2009, 2011), we hypothesized that tactile stimulation should be more pleasant when delivered by another person than when self-applied (self-touch). That is, being stroked by means of a given texture might evoke more intense sensations and stronger emotions than those that are elicited by self-stimulation. Finally, given the results obtained in a number of neurophysiological studies (Löken et al., 2009; Vallbo et al., 1999), we expected to observe more pleasant judgments from the stimulation of the hairy as compared to the glabrous skin. 


\section{Experiment 1}

\subsection{Methods}

\subsubsection{Participants}

Sixteen participants took part in this experiment ( 9 female, 7 male), with a mean age of 26.6 years (age range: 21-36 years). The participants reported normal tactile sensitivity and all but one were right-handed by self-report. None of the participants reported the presence of peripheral nerve damage. The male participants were instructed to shave their cheeks prior to taking part in the study. The experimental session lasted for about 75 min and the participants received a £5-10 gift voucher in return for taking part in the study. The participants gave their written informed consent prior to their taking part in the experiment. The study was performed in accordance with the ethical standards laid down in the 1991 Declaration of Helsinki and received ethical approval from the local ethics committee.

\subsubsection{Stimuli}

The stimuli consisted of ten rigid surfaces of the same area $(10 \times 10 \mathrm{~cm})$ made of cardboard, and covered by different textured materials: Oasis, tulle, satin, polyester, tinfoil, cling film, sandpaper, cotton, abrasive sponge, and kitchen sponge (see Fig. 1). Oasis is a special kind of modeling sponge commonly used to craft floral compositions. Tulle, satin, polyester and cotton represent examples of natural and synthetic textures that are frequently used to tailor items of clothing or bed linen. Tinfoil, cling film, sandpaper, abrasive sponge and kitchen sponge represent materials used in daily life activities.

\subsubsection{Procedure}

The participants were seated at a table and were instructed to rest their chin on a chinrest during the stimulation of their cheek and to rest their arm on the table during the stimulation of their hand. The stimulation was either delivered actively or passively. In the latter case, it was delivered by the experimenter. In both cases, the stimulation consisted of five stroking movements with the material being moved over a distance of $10 \mathrm{~cm}$ from the cheekbone to the jaw and from the palm to the fingertips. The same female experimenter tested all of the participants and was trained to apply the same force and

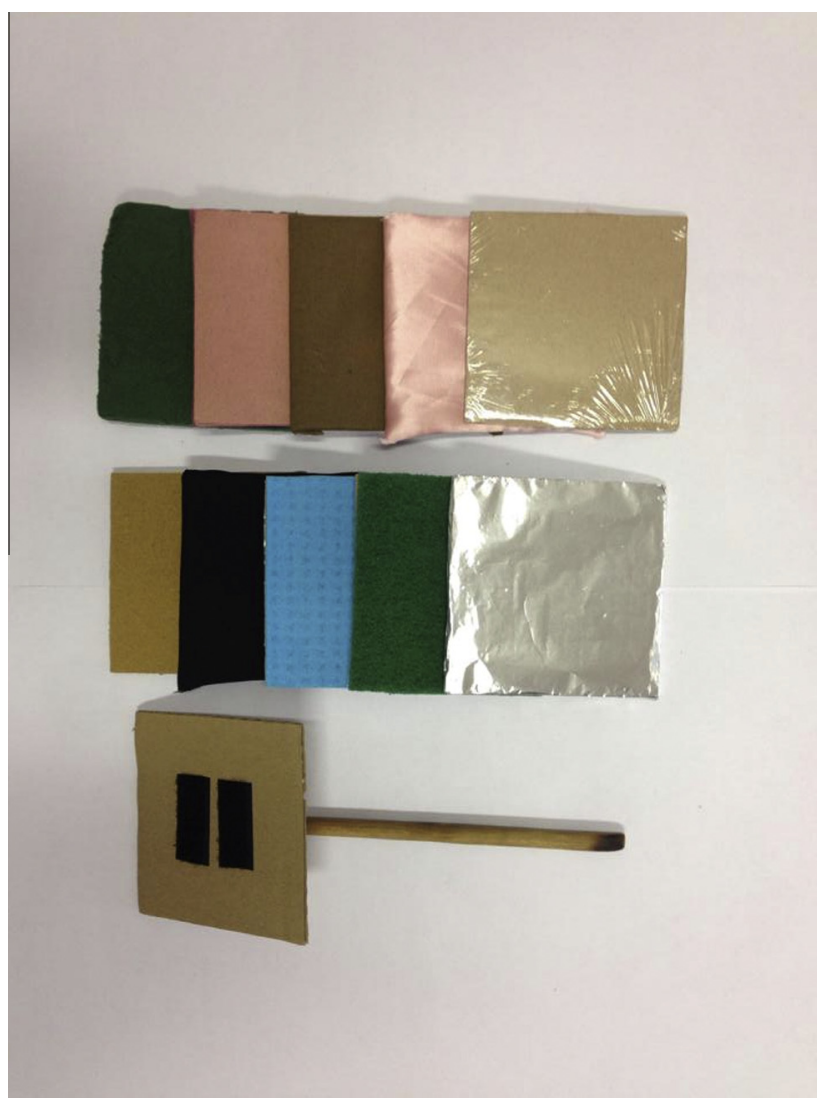

Fig. 1. Stimuli used in Experiment 1 (upper row from left to right: oasis, tulle, cotton, satin, cling film; lower row from left to right: sandpaper, polyester, kitchen sponge, abrasive sponge, tinfoil) and the set-up used to present them. 
the same speed of stimulation during the experiment. Just as in other previous studies regarding tactile information processing (Ballesteros, Reales, de León, \& Garcia, 2005; Hollins, Faldowski, Rao, \& Young, 1993; Klöcker et al., 2012; Picard, Dacremont, Valentin, \& Giboreau, 2003; though see Essick et al., 2010) the force of the exploration of the textures was not controlled. The speed of stimulation across the skin was not controlled but, in the passive condition, was held constant at approximately $15 \mathrm{~cm} / \mathrm{s}$. Although it is evident that the tactile stimulation applied by a human hand cannot be delivered as precisely as that applied by an electromechanical apparatus (e.g. a rotary tactile stimulator), this form of stimulus presentation certainly makes the experience of interacting with textures more ecologically valid. Under conditions of passive stimulation of the hand the experimenter was seated in front of the participants, who rested their wrists on a wooden block so that the experimenter could stimulate the palm and the fingertips. In the active hand stimulation condition, the participants were instructed to rest their hand in a fixed position and to move it towards the textured surface located in front of them, at the experimenter's signal. In the condition where a passive stimulation of the cheek was required, the experimenter stood approximately $50 \mathrm{~cm}$ from the left side of the participant's face and stimulated their cheek by means of a tool. The texture was glued to the top of the tool (see Fig. 1). The same tool was also used by the participants in the active stimulation of the cheek condition. For each trial, the participants had to rate the pleasantness and the roughness of the textures on visual analogue scales, with the words "unpleasant" and "pleasant" or "rough" and "smooth" as end-points (or anchors). The participant was required to express his/her judgment, by marking a point on the scale. Each scale was $10 \mathrm{~cm}$ long with the position marked by the participant subsequently being converted by the experimenter to a measure that ranged from $-5 \mathrm{~cm}$ (for "unpleasant" and "rough") to $+5 \mathrm{~cm}$ (for "pleasant" and "smooth"). The scales were presented on an A4 sheet of paper that was always visible to the participants. The pleasantness scale was always presented before the roughness scale. During both the passive and active exploration of the textures, the participants were blindfolded in order to avoid any influence of visual information on their tactile aesthetic judgments. The participants were instructed to move the blindfold away from their eyes only to rate their preferences on the scales. Ear plugs were worn by the participants in order to dampen any sounds associated with the contact and/or friction with the various textures (cf. Guest, Catmur, Lloyd, \& Spence, 2002).

\subsection{Results}

The data were analyzed with STATISTICA 6.0 (StatSoft, Italy). The relationship between the two dependent variables, i.e., pleasantness and roughness, was assessed by calculating the Pearson's correlation coefficient. This analysis revealed the presence of a significant positive correlation between the two variables: $r=.927, p<.001$ (one tailed). Next, we conducted two repeated measures analyses of variance (ANOVAs; one for each dependent variable: pleasantness and roughness) with the within-participant factors of material (ten textures), body site (cheek vs. hand), and mode of exploration (active vs. passive).

The analysis conducted on the pleasantness ratings revealed a significant main effect of material $[F(9,135)=16.60, p$ $<.001, \mathrm{y}^{2}=0.41$ ], showing that the 10 textures were judged differently by the participants in terms of their pleasantness. The main effects of body site and mode of exploration were not significant ([all $F(1,15)<1$; n.s.]). A significant interaction was also observed between material and body site $\left[F(9,135)=4.44, p<.001, \eta^{2}=0.01\right]$, as well as an interaction between material and mode of exploration $\left[F(9,135)=3.06, p=.002, \mathrm{n}^{2}=0.005\right]$. A post hoc test (corrected with Newman-Keuls' pro-cedure) on the material by body site interaction revealed that the cling film $(p<.001)$ was rated as more pleasant when explored with the cheek, whereas the kitchen sponge $(p=.01)$ was judged as more pleasant when explored with the palm of the hand. Furthermore, a Newman-Keuls' corrected post hoc test on the interaction between material and mode of explo-ration revealed that the oasis was rated as more pleasant when passively explored as compared to when it was actively explored $(p$ $<.001$ ).

The ANOVA also revealed a three-way interaction between material, body site, and mode of exploration $[F(9,135)=2.22, p$ $\left.=.02, \eta^{2}=0.004\right]$. Two separate ANOVAs, one for each body site, were performed in order to explore this result further. The ANOVA performed on the hand condition revealed a significant main effect of material $\left[F(9,135)=13.66, p<.001, \eta^{2}=0.43\right]$, and a significant interaction between material and mode of exploration $\left[F(9,135)=2.69, p=.006, \eta^{2}=0.01\right]$. A post hoc analysis of this interaction (Newman-Keuls' corrected) revealed that oasis $(p=.003)$ and cling film $(p=.03)$ were both rated as more unpleasant when explored actively than when explored passively. The ANOVA conducted on the cheek data highlighted the presence of a significant main effect of material $\left[F(9,135)=16.44, p<.001, \eta^{2}=0.47\right]$, and a significant interaction between material and mode of exploration $\left[F(9,135)=2.54, p=.01, \mathrm{\eta}^{2}=0.009\right]$. A New-man-Keuls' corrected post hoc test on the interaction revealed that the abrasive sponge $(p=.004)$ was judged as being more unpleasant when actively explored on the cheek than when the same material was passively presented on this part of the body (see Fig. 2).

The ANOVA conducted on the roughness data revealed a significant main effect of material $\left[F(9,135)=83.92, p<.001, \eta^{2}=\right.$ 0.77], showing that the textures were rated as different in terms of their roughness. The main effects of gender, body site, and exploration mode were all non-significant $([a l l ~ F(1,15)<1$; n.s.]). Furthermore, the results revealed a significant interaction between material and body site $\left[F(9,135)=2.71, p=.006, \eta^{2}=0.004\right]$. Post-hoc tests (corrected with Newman-Keuls' procedure) revealed that sandpaper was rated as rougher when explored with the hand than with the cheek $(p=.01)$, whereas the kitchen sponge was rated as rougher when explored with the cheek than with the hand $(p=.02)$. 


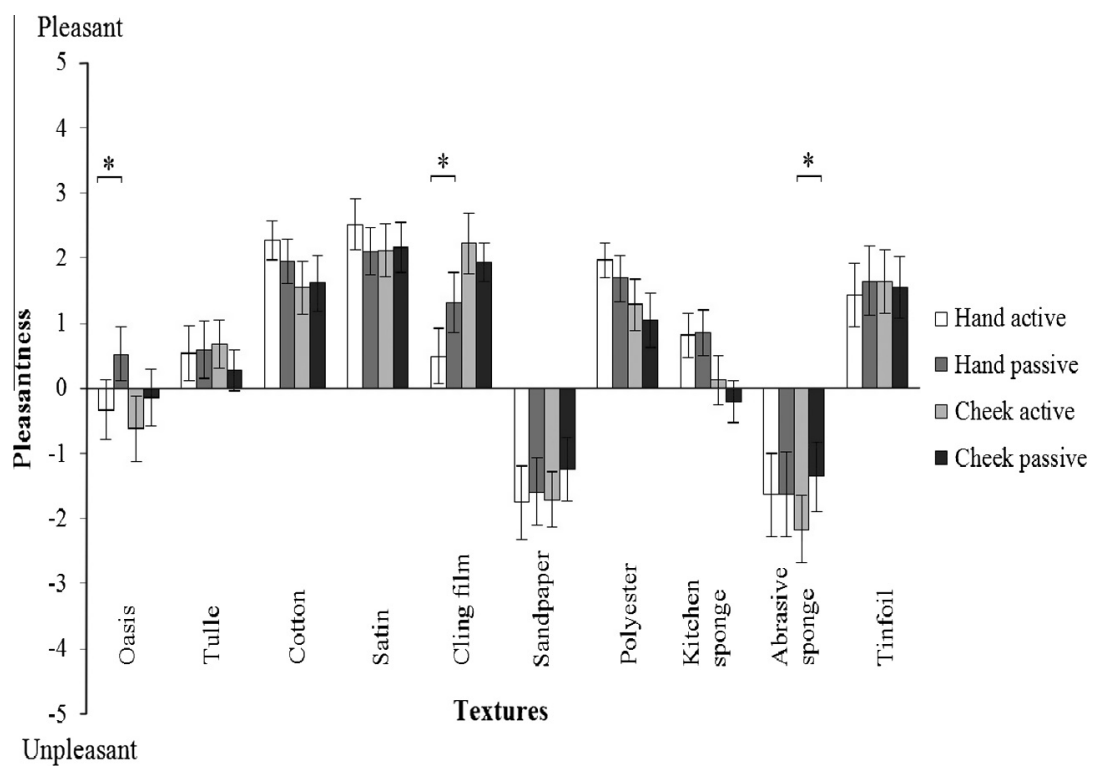

Fig. 2. Results of Experiment 1. Participants' mean ratings for the active and passive exploration of the different textures. Error bars represent the standard errors of the means. Asterisks indicate the presence of a significant difference between the two conditions.

\subsection{Discussion}

The results of Experiment 1 clearly highlight the presence of significant differences in participants' aesthetic and roughness judgments as a function of the material being explored. Furthermore, as demonstrated by the presence of a strong correlation between the judgments made on the two rating scales, pleasantness and roughness appear to follow a similar trend. Specifically, smoother textures were rated as more pleasant, and rougher textures were considered as more unpleasant, just as predicted (Ekman, Hosman, \& Lindström, 1965; Essick et al., 2010; Major, 1895; Ripin \& Lazarsfeld, 1937; Verrillo, Bolanowski, \& McGlone, 1999; Zampini, Guest, \& Spence, 2003). One might also hypothesize that rough materials are perceived as potentially harmful (rubbing the body with a piece of sandpaper can certainly abrade/damage the skin surface) and this could reinforce the experienced unpleasantness. Interestingly, the same line of reasoning could also be applied to those individuals who are affected by an allergy to specific materials that may have a distinctive associated texture, as in the case of the wool allergy (Mortensen, 1979). In fact, it might be that tactile attributes that are widely evaluated as pleasant (e.g., softness; Hollins et al., 1993; Picard et al., 2003) are perceived as unpleasant and dangerous by those individuals who are affected by such an allergy (Mortensen, 1979).

Moreover, the roughness data can be discussed in terms of the presence of a tactile 'mere exposure effect' (Gallace \& Spence, 2011a; Suzuki \& Gyoba, 2008). That is, people tend to prefer those stimuli that they have been exposed to previously (i.e., that they are more familiar with) as compared to others that have not experienced previously (Harrison, 1977; Jakesch \& Carbon, 2012; Zajonc, 1968, 1980, 2001). For instance, one might expect that those who are more used to work with certain rough materials, such as sculptors or carpenters, might be expected to rate rougher texture such as sandpaper as less unpleasant when compared to the rest of the population. The same reasoning could also be applied to those working in wool trade (Binns, 1926, 1934, 1937). Nevertheless, in the present study, we did not directly assess our participants' previous experience with textured materials. Therefore, future studies should certainly address this interesting issue.

Although the mode of exploration (active vs. passive) and the site of stimulation did not exert any significant main effect on participants' tactile judgments in the present study, they showed some interesting and significant interactions with the materials that were presented. More specifically, the oasis and the cling film were rated as more unpleasant when actively explored as compared to the passive presentation of these stimuli on the participant's hand. One might speculate about the fact that active exploration procedures (having as they do the primary goal of acquiring information about objects; Purves et al., 2001) facilitate the recognition of the texture and consequently reinforces the aversion for those textures that are memorized as aversive. Alternatively, or in addition, the enhanced pleasantness of certain materials experienced during conditions of passive stimulus exploration might be explained with reference to ecological factors. In fact, these kinds of stimuli might remind the participants of (or may have been treated by our participants' brains as) grooming and nurturing stimuli (Dunbar, 2010).

Given the presence of differences between the skin characteristics of the cheek and the palm of the hand (in terms of the distribution of receptor types and of the amount of bodily hair), we also expected to find a difference in participants' judgments as a function of the body site stimulated. Nevertheless, we only found significant interactions between the site of the 
body stimulated and the material presented. Specifically, the kitchen sponge was rated as smoother and more pleasant when presented on the hand than on the cheek, the cling film was rated as more pleasant when presented on the cheek as compared to the hand, and the sandpaper as rougher when explored with the hand than with the cheek. That is, the participants' responses to the various textures were not always the same for both parts of the body that were stimulated by the textures. A possible reason that might account for our failure to find a significant main effect of body site relates to the fact that we did not control the speed of stimulation. Although CT fibers respond to a large range of velocities of stimulation, their firing frequency is higher within the $1-10 \mathrm{~cm} / \mathrm{s}$ range of stimulus velocity (see Löken et al., 2009). Importantly, this preferred range of stimulation has been shown to be correlated with subjective pleasantness ratings (Löken et al., 2009). Hence, our stimulation protocol may simply not have elicited a vigorous enough response from the CT fibers in the hairy skin. In order to assess the role of the "body site" on our participants' aesthetic judgments, and in order to control the speed of tactile stimulation, we performed an additional experiment.

\section{Experiment 2}

\subsection{Methods}

\subsubsection{Participants}

Twelve right handed participants (10 female, 2 male) with a mean age of 22.8 years (ranging from 19-25 years) took part in this study. They reported normal tactile sensitivity and were all right-handed. The experimental session lasted for about $75 \mathrm{~min}$ and the participants gave written consent prior to their participation in the experiment. This study was performed in accordance with the ethical standards laid down in the 1991 Declaration of Helsinki and received the approval of the local ethics committee.

\subsubsection{Stimuli}

Five out of ten of the textures that had been used in Experiment 1 were chosen as stimuli for Experiment 2. The selected textures were those that had given rise to the highest pleasantness and unpleasantness ratings in Experiment 1: Oasis, satin, tinfoil, sandpaper and abrasive sponge (see Fig. 3).

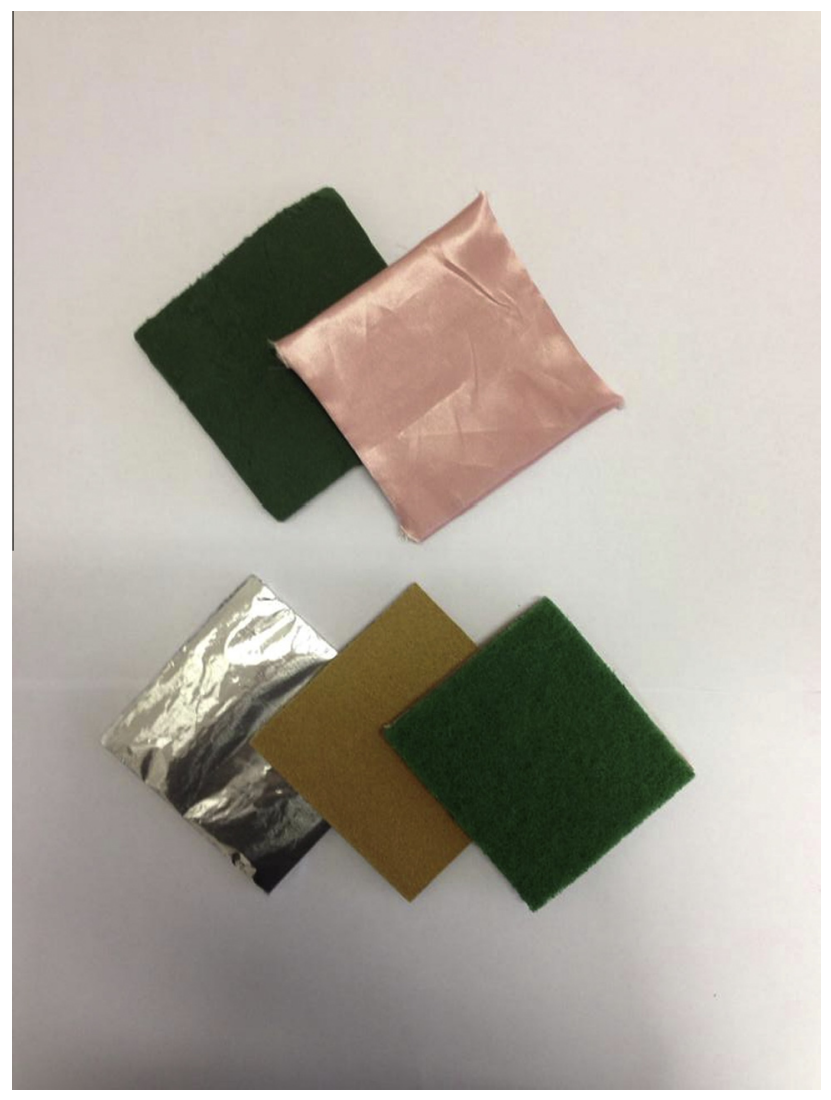

Fig. 3. Stimuli used in Experiment 2 (upper row from left to right: oasis, satin; lower row from left to right: tinfoil, sandpaper, abrasive sponge) and the setup used to present them. 


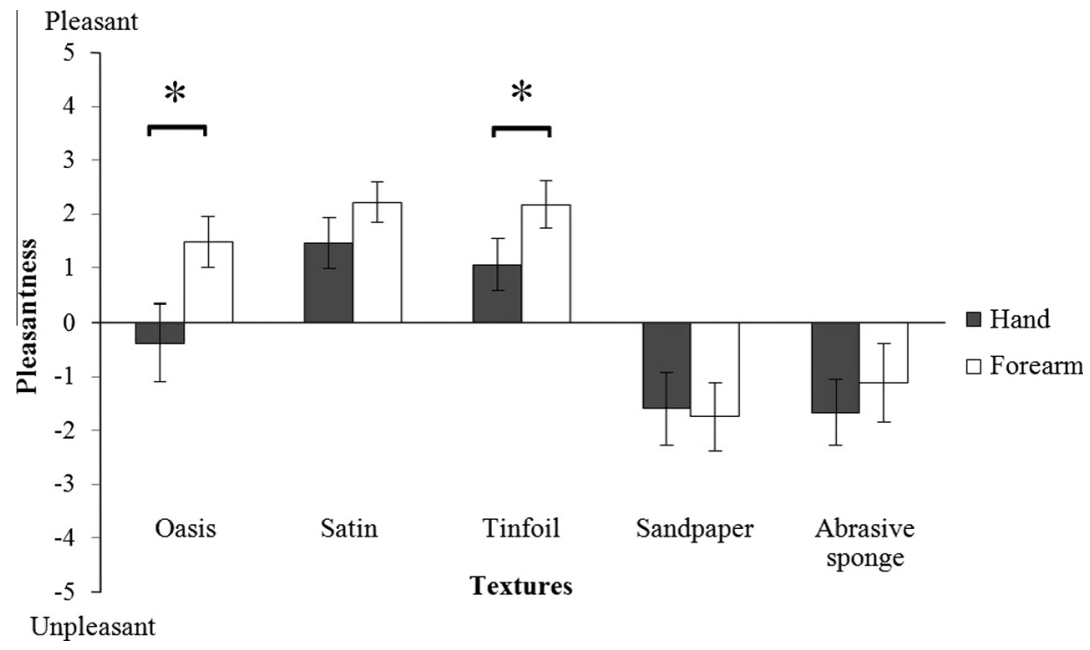

Fig. 4. Results of Experiment 2. Participants' mean ratings for the stimulation of the hand and the forearm by means of the different textures. Error bars represent the standard errors of the means. Asterisks indicate the presence of a significant difference between the two conditions.

\subsubsection{Procedure}

The participants were seated in front of the experimenter and rested their arms on the table with their hands facing palm upwards. The inner surface of their arms or their palms and fingertips, of the right or left arms, were stimulated with the different textures. In this experiment, the textures were only passively explored and the stimulation was always delivered by the same female experimenter. On each trial, the stimulus consisted of five stroking movements performed in the same direction, i.e., from the forearm to the wrist in the case of the presentation on the arm and from the palm to the fingertips during the stimulation of the participant's hand. The skin was stimulated over a distance of $10 \mathrm{~cm}$. The experimenter controlled the speed of stimulation, that was set at $5 \mathrm{~cm} / \mathrm{s}$ (based on the known preferred response range for CT fibers: 1-10 cm/ s; Löken et al., 2009), by following the movement of a cursor on a PC screen placed next to the participant's arms. The force of the stimulation was not controlled as in other studies (Ballesteros et al., 2005; Hollins et al., 1993; Klöcker et al., 2012; Picard et al., 2003), but the experimenter was trained to apply the same gentle pressure on the participant's skin during the entire experimental session. The participants were blindfolded and wore sound-proof headphones in order to prevent any effect of visual and auditory information resulting from the exploration of the textures or the movement of the cursor on the screen. On each trial, the participants were instructed to rate the pleasantness of the material on a $10 \mathrm{~cm}$ scale (consequently converted by the experimenter into scores that ranged from -5 to $+5 \mathrm{~cm}$, respectively unpleasant and pleasant), just as in Experiment 1 .

\subsection{Results}

The data were normally distributed, thus a repeated measures ANOVA on the pleasantness ratings was conducted with the factors of body site (hand vs. forearm), side (left vs. right), and material (five textures). Since the "side" factor was not significant $[F(1,11)<1]$, we collapsed the data and conducted another repeated measures ANOVA excluding this factor. The analysis revealed the presence of a significant main effect of body site $\left[F(1,11)=8.50, p=.01, \mathrm{j}^{2}=0.03\right]$, indicating higher pleasantness ratings for the stimulation delivered to the participant's forearm $(M=0.60, S D= \pm 1.16)^{2}$ as compared to the stimulation of their hand $(M=-0.22, S D= \pm 1.53)$. The main effect of material was also significant $\left[F(4,44)=14.28, p<.001, \mathrm{\eta}^{2}=\right.$ 0.47]: Satin was rated as the most pleasant material $(M=1.84, S D= \pm 1.33)$, followed by tinfoil $(M=1.61, S D= \pm 1.36)$, oasis $(M=$ $0.54, S D= \pm 1.94)$, abrasive sponge $(M=-1.38, S D= \pm 2.21)$, and sandpaper $(M=-1.66, S D= \pm 2.19)$. The interaction between body site and material was also significant $\left[F(4,44)=4.76, p=.01, \mathrm{y}^{2}=0.02\right]$. A Newman-Keuls' corrected post hoc test on this interaction revealed a significant difference between the presentation of the textures on the participant's hand and on their forearm for oasis $(p<.001)$ and tinfoil $(p=.009)$. These two textures were rated as more pleasant when presented on the forearm than when presented on the hand (see Fig. 4).

\subsection{Discussion}

The significant effect of 'material' replicates and confirms the results obtained in Experiment 1 . That is, smooth textures such as satin and tinfoil were rated as the most pleasant, whereas rough materials such as sandpaper and abrasive sponge were rated as the most unpleasant. Moreover, the results highlight the presence of a significant difference between the

\footnotetext{
2 The abbreviation " $M$ " indicated the mean of the scores, whereas the abbreviation "SD" refers to the standard deviation.
} 
judgments concerning the stimuli delivered to the participants' forearms as compared to their hands. Namely, tactile stimuli were rated as more pleasant when presented on the participant's forearm than when presented on their hand instead. This effect might be linked to the principal characteristics of the skin sites stimulated and to their fundamental function. In fact, while the palm of the hand is glabrous and specialized in both discriminating and recognizing the properties of the surfaces being explored (Johansson \& Vallbo, 1979; Löken, Evert, \& Wessberg, 2011), the forearm is covered by hairs and it usually contributes to convey emotional information (Guest et al., 2011; Hertenstein et al., 2006). This difference is mainly (but not only) related to the presence of diverse neural fibers that innervate different areas of the body. That is, while the forearm is innervated by both $A \beta$ fibers (specialized in discriminative touch) and CT fibers (thought to mediate the more emotional aspects of touch), the palm of the hand lacks any innervation by CT fibers (Liu et al., 2007; Vallbo et al., 1999). In Experiment 2, by using a stimulation velocity that elicits more vigorous responses from the CT fibers (Löken et al., 2009), we found a significant difference between the participants' responses to the stimuli presented to the two areas of the body stimulated, suggesting that the stimulation of hairy skin is more pleasant than the stimulation of the glabrous skin (Essick et al., 2010; Guest et al., 2011; Löken et al., 2009). In fact, participants' pleasantness judgments for two out of five textures were enhanced when the stimuli were presented on the forearm as compared to the palm of the hand.

\section{General discussion}

The results of the two experiments reported in the present study provide some preliminary evidence regarding human aesthetic preferences in the tactile modality. As far as the type of stimulus presentation (active vs. passive) is concerned, we found that this factor affected the subjective ratings of certain textures. In particular, a number of the materials presented (oasis and cling film on the hand and abrasive sponge on the cheek) evoked even more unpleasant ratings when actively explored as compared to when passively presented. One might reasonably think that the haptic exploration of these stimuli could have made the participants gather more detailed information, facilitating the recognition of the material explored and consequently affecting the aesthetic judgments. For instance, realizing that one has been stroked with a piece of abrasive sponge might evoke an aversive reaction, thus modulating the judgments regarding such texture. Although a reduction of tactile sensitivity during movement execution has been demonstrated in a number of studies, recent work by Juravle and her colleagues (2013) has revealed that this phenomenon, known as tactile sensory suppression (Bays et al., 2006, 2007; Blakemore, Wolpert, \& Frith, 2000; Blakemore et al., 1998; Chapman \& Beauchamp, 2006; Gallace et al., 2010), only occurs for irrelevant tactual features in a given task and is thus context-dependent. That is, whenever an active movement is exe-cuted with the goal of gaining information about a texture (e.g. an exploratory movement), tactile information processing is enhanced rather than suppressed (Juravle et al., 2013). Moreover, previous results concerning the effect of active and passive stimulation on people's sensory and emotional judgments regarding tactile stimuli have shown that the active exploration of the textures may lead to a less pleasant and intense percept as compared to when they are explored passively (Guest et al., 2011).

Conversely, the greater dislike of certain textures when actively explored can be interpreted as reflecting an increase in pleasantness during the conditions of passive exploration. In fact, being stimulated by another individual has been shown to be more pleasant than self-stimulation (Guest et al., 2009, 2011), thus providing another demonstration of the strong effect of interpersonal touch on the evaluation of tactile pleasantness (Crusco \& Wetzel, 1984; Fisher, Rytting, \& Heslin, 1976; see Gallace \& Spence, 2010, for a review). Here, it is important to highlight the fact that social factors (such as the gender of both experimenter and participant or their age), even though not directly manipulated in the present study, might have affected our results. In particular, it is reasonable to think that the congruence/incongruence of gender between experimenter and participant might influence those conditions where the passive stimulation of the participant's skin was delivered and thus mediate the experience regarding the stimulation (Gazzola et al., 2012). The influence of social factors on passive hedonic stimulation is surely an aspect that merits future study.

In Experiment 1, a number of significant interactions were observed between body site and texture for both the roughness and pleasantness ratings. Specifically, the kitchen sponge was perceived as smoother and more pleasant when placed on the hand as compared to the cheek, the cling film as more pleasant on the cheek than on the hand and the sandpaper was rated as rougher on the hand than on the cheek. It would seem likely that the kitchen sponge is preferred when presented on the hand because it is perceived as smoother on the palm than on the cheek. Furthermore, the greater roughness perceived when touching the sandpaper with the hand might depend on the greater discriminative abilities of the glabrous skin (McGlone et al., 2007, 2014). As far as the cling film is concerned, it is possible that the greater unpleasantness felt when this material is explored with the hand depends on the fact that the repeated stroking of the cling film with the palm (and particularly with the fingertips) may result in a loss of the tension in the material, thus creating an unpleasant blemish in the texture.

Despite our initial expectations, we did not observe more pleasant ratings coming from the stimulation of the cheek over the stimulation of the palm of the hand (except to the case of the cling film). By contrast, in Experiment 2, in which the stimuli were presented on the palm of the hand and on the forearm at a controlled velocity (in order to effectively induce an increased frequency of CT firing; Löken et al., 2009), the results showed that the stroking of the forearm evoked higher ratings of pleasantness, compared to the hand. This result would seem to be related to the specialization of different kinds of skin (Weinstein, 1968). More specifically, while the glabrous skin is more specialized for discriminative touch, and this is 
particularly true for the palm of the hand (Sathian \& Zangaladze, 1996), the hairy skin is primarily involved in the more emotional aspects of touch (Löken et al., 2009; McGlone et al., 2007). This seems to be related to the fact that the hairy skin is densely innervated by CT fibers (that are specialized for hedonic sensations) and that their stimulation evokes larger affective responses (Essick et al., 2010; Löken et al., 2009; McGlone et al., 2007, 2014). In fact, it has been suggested that these fibers might be part of a primitive neural network (the limbic system) that might play an important role in the regulation of emotional, hormonal, and affiliative responses (McGlone et al., 2007, 2012, 2014). Importantly, all of these responses have been shown to be involved in the social behavior of primates (e.g., such as in grooming and nurturing; Dunbar, 2010). In order to explain the effect of the stimulation of different body parts on the participants' judgments it is also worth mentioning that the hairy and glabrous parts of the body differ not only in terms of main innervation but also in terms of the thickness of the skin. That is, the glabrous skin has been shown to be thicker than the hairy skin (Nouveau-Richard, Monot, Bastien, \& De Lacharriere, 2004; Whitton \& Everall, 1973). In fact, the thickness of the skin might also play a role in mediating pleasant sensations.

A number of factors might help to explain why the stimulation of the cheek did not evoke higher pleasantness ratings compared to the stimulation of the hand. This result might be, at least in part, the consequence of a lack of control over the velocity of stimulation. In fact, the CT fibers, present only in the hairy skin (included the face skin, as originally shown by Nordin (1990)), have a preferential range of response (1-10 cm/s; Liu et al., 2007; Löken et al., 2009; Vallbo et al., 1999) and the velocity of stimulation was not controlled in Experiment 1. However, it cannot be claimed that our stimuli did not activate the CT fibers at all. We likely elicited some kind of response from CT fibers, but at a lower frequency of firing (as compared to the stimulation presented in Experiment 2).

A second factor that might have given rise to the lack of higher pleasantness ratings for the stimulation of the cheek might be related to the more social aspects of touch (e.g., Gallace \& Spence, 2010). Being stroked on the face might elicit a sense of intrusion in the personal space (perhaps also modulated by the gender of the experimenter; see Gazzola et al., 2012), which might in turn affect the participants' hedonic judgments (Ackerley, Saar, McGlone, \& Wasling, 2014; Essick, James, \& McGlone, 1999; Gallace \& Spence, 2014). Finally, it should be considered that the face and forearm are represented differently on the somatosensory cortex (Penfield \& Boldrey, 1937), with more cortical volume being dedicated to the representation of the face as compared to the representation of the arm. Given that the relative size of the somatosensory representations is directly correlated with the number of fibers that innervate each body site, this difference corresponds to a higher spatial resolution for those stimuli that are presented on the hands as compared to the cheek (Bensmaia \& Yau, 2011), although the face is one of the most sensitive areas of the body (Weinstein, 1968). Whether or not the size of the somatosensory representation for different body parts is related to different aesthetic judgments concerning tactile stim-uli is another issue that certainly deserves further investigation in the years to come.

In Experiment 1, participants' judgments regarding the dimensions of roughness and pleasantness were strongly correlated. The evidence about an association between 'smoothness and pleasantness' and 'roughness and unpleasantness' is consistent with previous research on this topic (Ekman et al., 1965; Essick et al., 2010; Major, 1895; Ripin \& Lazarsfeld, 1937; Verrillo et al., 1999; Zampini et al., 2003). Importantly, the dimension of roughness is intrinsically linked with the concept of friction: that is, the rougher a texture, the greater the frictional forces that are needed to explore it. As a consequence, friction would also seem to play a role in our participants' judgments regarding the pleasantness/unpleasantness of the textures. In fact, it has been shown that greater friction is generally correlated with feelings that are rated as less pleasant (Ekman et al., 1965; Klöcker et al., 2013). However, the relationship between friction, roughness, and pleasantness is not so straightforward, and a number of other factors have been shown to influence the sensation of roughness and pleasantness (Essick et al., 2010). For example, a high level of moisture in the fingertips results in rough materials being perceived as more pleas-ant and smooth materials as less pleasant in comparison to conditions when the skin moisture level is lower (Klöcker et al., 2012). Moreover, the velocity applied during the stimulation of hairy skin is correlated with pleasantness ratings (Cascio et al., 2008; Essick et al., 2010; Löken et al., 2009).

The data obtained with the presentation of the oasis certainly deserves special mention. In fact, in both Experiments 1 and 2, the participants' ratings regarding the pleasantness of this material/texture (see Figs. 2 and 4), differed from those obtained with the other textures. In particular, it seems that a faster stimulation $(15 \mathrm{~cm} / \mathrm{s}$; as compared to a slower stimulation, $5 \mathrm{~cm} / \mathrm{s}$ ) evoked an increased feeling of pleasantness for this material but not for others. This might be taken to suggest a selective effect of velocity for the oasis as compared to other materials. It is possible that the slower exploration of oasis allowed our participants to gain more information about it, thus resulting in a different percept as compared to the faster exploration of the same material.

It can be speculated that aesthetic judgments are not merely the product of current perceptual inputs, but that both any previous experiences with the materials and higher order cognitive factors affect people's preferences (Gallace \& Spence, 2014; McCabe, Rolls, Bilderbeck, \& McGlone, 2008). In fact, as briefly outlined earlier, rough textures could have been perceived as slightly painful/annoying and the repeated stimulation of the skin by means of an unpleasant texture may have enhanced the feeling of discomfort, consequently resulting in more extreme ratings. Moreover, the recognition of the texture during the stimulation is likely to have affected the participants' judgments of pleasantness. That is, the perceived pleasantness of certain textures, once recognized, may be reduced by the realization that the material is not usually judged in terms of its pleasantness (e.g., such as for the cling film). Certainly, the study of the top-down mechanisms involved in the formulation of the aesthetic tactile judgments is another aspect that deserves further investigation. 
In conclusion, the results of the present study confirm the presence of some basic principles at the basis of human tactile aesthetic judgments, and, in particular, the association between perceived pleasantness and smoothness of surfaces. Moreover, the results presented here would seem to suggest the existence of a complex interaction between tactile pleasantness, the physiology of the haptic system, the microgeometric structure of the materials presented, and the way in which tactile stimuli are delivered (not to mention the more social aspects of tactile stimulation).

The results of studies of tactile aesthetics might be compared with our knowledge regarding visual and auditory aesthetics, revealing further similarities and differences between these senses. A deeper understanding of tactile aesthetics are certainly not only of theoretical relevance but also extremely useful in the applied field (Gallace \& Spence, 2014; Spence \& Gallace, 2011). That is, information concerning tactile preferences might be expected to help designers and engineers to create objects and materials that appeal more to our senses and that are more effective in eliciting certain emotional responses from a potential consumer. Furthermore, understanding the mechanisms of tactile aesthetics might also be of great use in a number of social settings (e.g., where social touch is used with a therapeutic function) as well as for helping visuallyimpaired and sighted individuals, to improve their experience while visiting museums and art galleries (Gallace \& Spence, 2014; Spence, 2008; Spence \& Gallace, 2008).

\section{Acknowledgments}

RE took part in the international program "EXTRA PLUS", funded by the "Fondazione Cariplo". AG and RE were funded by CARITRO Foundation, IRIFOR Trentino and the TELECOM Italy Foundation.

\section{References}

Ackerley, R., Saar, K., McGlone, F., \& Wasling, H. B. (2014). Quantifying the sensory and emotional perception of touch: Differences between glabrous and hairy skin. Frontiers in Behavioral Neuroscience, 8, 34.

Andrew, D. (2010). Quantitative characterization of low threshold mechanoreceptor inputs to lamina I spinoparabrachial neurons in the rat. Journal of Physiology, 588, 117-124.

Ballesteros, S., Reales, J. M., de León, L. P., \& Garcia, B. (2005). The perception of ecological textures by touch: Does the perceptual space change under bimodal visual and haptic exploration? In Proceedings of Eurohaptics conference, 2005 and symposium on haptic interfaces for virtual environment and teleoperator systems, 2005. World Haptics 2005 (pp. 635-638). Los Alamitos, CA: IEEE Computer Society.

Bays, P. M., Flanagan, J. R., \& Wolpert, D. M. (2006). Attenuation of self-generated tactile sensations is predictive, not postdictive. PLoS Biology, 4, e28.

Bays, P. M., \& Wolpert, D. M. (2007). Predictive attenuation in the perception of touch. In P. Haggard, Y. Rosetti, \& M. Kawato (Eds.), Attention E performance XXII, Sensorimotor foundations of higher cognition (pp. 339-358). Oxford: Oxford University Press.

Bensmaia, S. J., \& Yau, J. M. (2011). The organization of function of somatosensory cortex. In M. Hertenstein \& S. Weiss (Eds.), The handbook of touch (pp. 161-187). New York: Springer.

Bergmann Tiest, W. M., \& Kappers, A. (2006). Haptic and visual perception of roughness. Acta Psychologica, 124, 177-189.

Bhushan, N., Rao, A. R., \& Lohse, G. L. (1997). The texture lexicon: Understanding the categorization of visual texture terms and their relationship to texture images. Cognitive Science, 21, 219-246.

Binns, H. (1926). The discrimination of wool fabrics by the sense of touch. British Journal of Psychology, 16, $237-247$.

Binns, H. (1934). A visual and tactual analysis of typical Bradford wool tops. Journal of the Textile Institute, 25, T331-T354

Binns, H. (1937). Visual and tactual 'judgement' as illustrated in a practical experiment. British Journal of Psychology, 27, 404-410.

Björnsdotter, M., Löken, L., Olausson, H., Vallbo, Å., \& Wessberg, J. (2009). Somatotopic organization of gentle touch processing in the posterior insular cortex. Journal of Neuroscience, 29, 9314-9320.

Björnsdotter, M., Morrison, I., \& Olausson, H. (2010). Feeling good: On the role of C fiber mediated touch in interoception. Experimental Brain Research, 207, $149-155$

Blakemore, S. J., Wolpert, D. M., \& Frith, C. D. (1998). Central cancellation of self-produced tickle sensation. Nature Neuroscience, 1, 635-640. Blakemore,

S. J., Wolpert, D., \& Frith, C. D. (2000). Why can't you tickle yourself? NeuroReport, 11, R11-R16.

Cascio, C. J., McGlone, F. P., Folger, S., Tannan, V., Baranek, G., Pelphrey, K. A., et al (2008). Tactile perception in adults with autism: A multidimensional psychophysical study. Journal of Autism and Developmental Disorders, 38, 127-137.

Chapman, C. E., \& Beauchamp, E. (2006). Differential controls over tactile detection in humans by motor commands and peripheral reafference. Journal of Neurophysiology, 96, 1664-1675.

Chapman, C. E., Bushnell, M. C., Miron, D., Duncan, G. H., \& Lund, J. P. (1987). Sensory perception during movement in man. Experimental Brain Research, 68, $516-524$

Coleman, F. J. (1965). Can a smell or a taste or a touch be beautiful? American Philosophical Quarterly, 2, 319-324.

Craig, A. D. (2002). How do you feel? Interoception: The sense of the physiological condition of the body. Nature Reviews Neuroscience, 3, 655-666. Craig,

A. D. (2009). How do you feel-now? The anterior insula and human awareness. Nature Reviews Neuroscience, 10, 59-70.

Crick, F. (1988). What mad pursuit. New York: Basic Books.

Crusco, A. H., \& Wetzel, C. G. (1984). The Midas touch the effects of interpersonal touch on restaurant tipping. Personality and Social Psychology Bulletin, 10, 512-517.

Dunbar, R. I. M. (2010). The social role of touch in humans and primates: Behavioral function and neurobiological mechanisms. Neuroscience and Biobehavioral Reviews, 34, 260-268.

Ekman, G., Hosman, J., \& Lindström, B. (1965). Roughness, smoothness, and preference: A study of quantitative relations in individual subjects. Journal of Experimental Psychology, 70, 18-26.

Essick, G. K., James, A., \& McGlone, F. P. (1999). Psychophysical assessment of the affective components of non-painful touch. NeuroReport, $10,2083-2087$.

Essick, G. K., McGlone, F., Dancer, C., Fabricant, D., Ragin, Y., Phillips, N., et al (2010). Quantitative assessment of pleasant touch. Neuroscience and Biobehavioral Reviews, 34, 192-203.

Fisher, J. D., Rytting, M., \& Heslin, R. (1976). Hands touching hands: Affective and evaluative effects of an interpersonal touch. Sociometry, 39, 416-421.

Francis, S., Rolls, E. T., Bowtell, R., McGlone, F., Browning, A., Clare, S., et al (1999). The representation of pleasant touch in the brain and its relationship with taste and olfactory areas. NeuroReport, 10, 453-459.

Gallace, A., \& Spence, C. (2010). The science of interpersonal touch: An overview. Neuroscience and Biobehavioral Reviews, 34, $246-259$.

Gallace, A., \& Spence, C. (2011a). Tactile aesthetics: Towards a definition of its characteristics and neural correlates. Social Semiotics, 21, 569-589. Gallace, A.,

\& Spence, C. (2011b). To what extent do Gestalt grouping principles influence tactile perception? Psychological Bulletin, 137, 538-561. Gallace, A., \& Spence, C.

(2014). In touch with the future: The sense of touch from cognitive neuroscience to virtual reality. Oxford: Oxford University Press. 
Gallace, A., Zeeden, S., Röder, B., \& Spence, C. (2010). Lost in the move? Secondary task performance impairs tactile change detection on the body. Consciousness and Cognition, 19, 215-229.

Galzigna, L. (1993). Il bello: Oggetto di emozione estetica nelle arti e nelle scienze [Beauty: The object of aesthetics in art and science]. In A. Argenton (Ed.), L'emozione Estetica [The aesthetic emotion] (pp. 68-80). Padova: Il Poligrafo.

Gazzola, V., Spezio, M. L., Etzel, J. A., Castelli, F., Adolphs, R., \& Keysers, C. (2012). Primary somatosensory cortex discriminates affective significance in social touch. Proceedings of the National Academy of Sciences of the USA, 109, e1657-e1666.

Guest, S., Catmur, C., Lloyd, D., \& Spence, C. (2002). Audiotactile interactions in roughness perception. Experimental Brain Research, 146, 161-171. Guest,

S., Dessirier, J. M., Mehrabyan, A., McGlone, F. P., Essick, G., Gescheider, G., et al (2011). The development and validation of sensory and emotional scales of touch perception. Attention, Perception E Psychophysics, 73, 531-550.

Guest, S., Essick, G. K., Dessirier, J. M., Blot, K., Lopetcharat, K., \& McGlone, F. P. (2009). Sensory and affective judgments of skin during inter- and interpersonal touch. Acta Psychologica, 130, 115-126.

Harrison, A. A. (1977). Mere exposure. In L. Berkowitz (Ed.). Advances in experimental social psychology (Vol. 10, pp. 39-83). New York: Academic.

Hertenstein, M. J., Keltner, D., App, B., Bulleit, B. A., \& Jaskolka, A. R. (2006). Touch communicates distinct emotions. Emotion, 6, $528-533$.

Hollins, M., Faldowski, R., Rao, S., \& Young, F. (1993). Perceptual dimensions of tactile surface texture: A multidimensional scaling analysis. Perception E Psychophysics, 54, 697-705.

Jakesch, M., \& Carbon, C. C. (2012). The mere exposure effect in the domain of haptics. PLoS ONE, 7, e31215.

Johansson, R. S., \& Vallbo, A. B. (1979). Tactile sensibility in the human hand: Relative and absolute densities of four types of mechanoreceptive units in glabrous skin. Journal of Physiology, 286, 283-300.

Juravle, G., McGlone, F., \& Spence, C. (2013). Context-dependent changes in tactile perception during movement execution. Frontiers in Psychology, $4,9$.

Klöcker, A., Arnould, C., Penta, M., \& Thonnard, J. L. (2012). Rasch-built measure of pleasant touch through active fingertip explorations. Frontiers in Neurorobotics, 6,5

Klöcker, A., Wiertlewski, M., Théate, V., Hayward, V., \& Thonnard, J. L. (2013). Physical factors influencing pleasant touch during tactile exploration. PLoS ONE, 8, e79085.

Lindgren, L., Westling, G., Brulin, C., Lehtipalo, S., Andersson, M., \& Nyberg, L. (2012). Pleasant human touch is represented in pregenual anterior cingulated cortex. NeuroImage, 59, 3427-3432.

Liu, Q., Vrontou, S., Rice, F. L., Zylka, M. J., Dong, X., \& Anderson, D. J. (2007). Molecular genetic visualization of a rare subset of unmyelinated sensory neurons that may detect gentle touch. Nature Neuroscience, 10, 946-948.

Löken, L. S., Evert, M., \& Wessberg, J. (2011). Pleasantness of touch in human glabrous and hairy skin: Order effects on affective ratings. Brain Research, 1417, 9-15.

Löken, L. S., Wessberg, J., Morrison, I., McGlone, F., \& Olausson, H. (2009). Coding of pleasant touch by unmyelinated afferents in humans. Nature Neuroscience, $12,547-548$.

Major, D. R. (1895). On the affective tone of simple sense-impressions. American Journal of Psychology, 7, 57-77.

McCabe, C., Rolls, E. T., Bilderbeck, A., \& McGlone, F. (2008). Cognitive influences on the affective representation of touch and the sight of touch in the human brain. Social Cognitive and Affective Neuroscience, 3, 97-108.

McGlone, F., Olausson, H., Boyle, J. A., Jones-Gotman, M., Dancer, C., Guest, S., et al (2012). Touching and feeling: Differences in pleasant touch processing between glabrous and hairy skin in humans. European Journal of Neuroscience, 35, 1782-1788.

McGlone, F., \& Reilly, D. (2010). The cutaneous sensory system. Neuroscience and Biobehavioral Reviews, 34, 148-159.

McGlone, F., Vallbo, A. B., Olausson, H., Löken, L., \& Wessberg, J. (2007). Discriminative touch and emotional touch. Canadian Journal of Experimental Psychology, 61, 173-183.

McGlone, F., Wessberg, J., \& Olausson, H. (2014). Discriminative and affective touch: Sensing and feeling. Neuron, 82, 737-755.

Morrison, I., Björnsdotter, M., \& Olausson, H. (2011). Vicarious responses to social touch in posterior insular cortex are tuned to pleasant caressing speeds. Journal of Neuroscience, 31, 9554-9562.

Mortensen, T. (1979). Allergy to lanolin. Contact Dermatitis, 5, 137-139.

Nordin, M. (1990). Low-threshold mechanoreceptive and nociceptive units with unmyelinated (C) fibres in the human supraorbital nerve. Journal of Physiology, 426, 229-240.

Nouveau-Richard, S., Monot, M., Bastien, P., \& De Lacharriere, O. (2004). In vivo epidermal thickness measurement: Ultrasound vs. confocal imaging. Skin Research and Technology, 10, 136-140.

Olausson, H. W., Cole, J., Vallbo, Å. B., McGlone, F., Elam, M., Krämer, H. H., et al (2008). Unmyelinated tactile afferents have opposite effects on insular and somatosensory cortical processing. Neuroscience Letters, 436, 128-132.

Olausson, H. W., Lamarre, Y., Backlund, H., Morin, C., Wallin, B. G., Starck, G., et al (2002). Unmyelinated tactile afferents signal touch and project to insular cortex. Nature Neuroscience, 5, 900-904

Paulus, M. P. (2007). Neural basis of reward and craving-a homeostatic point of view. Dialogues in Clinical Neuroscience, 9, $379-387$.

Penfield, W., \& Boldrey, E. B. (1937). Somatic motor and sensory representation. I. The cerebral cortex of man as studied by electrical stimulation. Brain, 60 , 389-443.

Picard, D., Dacremont, C., Valentin, D., \& Giboreau, A. (2003). Perceptual dimensions of tactile textures. Acta Psychologica, 114, 165-184.

Purves, D., Augustine, G. J., Fitzpatrick, D., Katz, L. C., LaMantia, A. S., McNamara, O., et al (2001). Neuroscience. Sunderland, MA: Sinauer Associates.

Ripin, R., \& Lazarsfeld, P. F. (1937). The tactile-kinaesthetic perception of fabrics with emphasis on their relative pleasantness. Journal of Applied Psychology, $21,198-224$

Rolls, E. T., O’Doherty, J. O., Kringelbach, M. L., Francis, S., Bowtell, R., \& McGlone, F. (2003). Representations of pleasant and painful touch in the human orbitofrontal and cingulated cortices. Cerebral Cortex, 13, 308-317.

Sathian, K., \& Zangaladze, A. (1996). Tactile spatial acuity at the human fingertip and lip: Bilateral symmetry and interdigit variability. Neurology, 46, $1464-1466$.

Spence, C. (2008). Making sense of touch: A multisensory approach to the perception of objects. In E. Pye (Ed.), The power of touch: Handling objects in museums and heritage contexts (pp. 45-61). Walnut Creek, California: Left Coast Press.

Spence, C., \& Gallace, A. (2008). Making sense of touch. In E. Chatterjee (Ed.), Touch in museums: Policy and practice in object handling (pp. 21-40). London: Berg.

Spence, C., \& Gallace, A. (2011). Multisensory design: Reaching out to touch the consumer. Psychology E Marketing, 28, $267-308$.

Suzuki, M., \& Gyoba, J. (2008). Visual and tactile cross-modal mere exposure effects. Cognition and Emotion, 22, $147-154$.

Vallbo, A. B., Olausson, H., \& Wessberg, J. (1999). Unmyelinated afferents constitute a second system coding tactile stimuli of the human hairy skin. Journal of Neurophysiology, 81, 2753-2763.

Verrillo, R. T., Bolanowski, S. J., \& McGlone, F. (1999). Subjective magnitude of tactile roughness. Somatosensory and Motor Research, 16, 352-360.

Weinstein, S. (1968). Intensive and extensive aspects of tactile sensitivity as a function of body part, sex, and laterality. In D. R. Kenshalo (Ed.), The skin senses (pp. 195-222). Springfield: Thomas.

Whitton, J. T., \& Everall, J. D. (1973). The thickness of the epidermis. British Journal of Dermatology, 89, 467-476.

Zajonc, R. B. (1968). Attitudinal effects of mere exposure. Journal of Personality and Social Psychology, 9, 1-28.

Zajonc, R. B. (1980). Feeling and thinking: Preferences need no inferences. American Psychologist, 35, 151-175.

Zajonc, R. B. (2001). Mere exposure: A gateway to the subliminal. Current Directions in Psychological Science, 10, $224-228$.

Zampini, M., Guest, D., \& Spence, C. (2003). The role of auditory cues in modulating the perception of electric toothbrushes. Journal of Dental Research, 82, 929-932. 